\title{
The Experimental Study of the Coal Wastage Caused by Rain in Open-Air Coal Yard
}

\author{
Lin Musong ${ }^{1}$, Su Wei', Chen Tiansheng ${ }^{1}$, Ma Xiaogian², Wu Wanqiang ${ }^{2 *}$, Yu Zhaosheng ${ }^{2}$, Yao Zhongliang ${ }^{2}$ \\ ${ }^{1}$ Electric Power Research Institute of Guangdong Power Grid Corporation, Guangzhou 510080, Guangdong Province, China \\ ${ }^{2}$ School of Electric Power, South China University of Technology, Guangzhou 510640, China
}

\begin{abstract}
Introduction:This paper introduced Rainfall simulation by using spray head, experimental study on power plant coal storage wastage produced by the influence of the rainfall.Discuss the different coal kinds, rainfall intensity ,rainfall time and the influence of coating agent on loss of coal.The results show that Can reduce the coal loss due to rain.
\end{abstract}

\section{Introduction}

National thermal power station number and each power plant coal accumulation is huge.Each year, the loss of economy is not measurement because of the rain coal.So, how to reduce the coal burning for rainfall loss is a present important subject. In this paper, based on simulated rainfall, experimental verification the rainfall how to influence on pile in actual situation. nozzle is used to simulate the natural rainfall in the experiments, to scour test pile. The aim of the experiment was to compare rainfall intensity, rainfall time and different types of covering agent affect the coal consumption, and get the method of reducing power plant coal consumption.

\section{Theoretical model of the rains scouring}

\subsection{The rains scouring calculation model}

Soil and water flow unit mass is taken in any position on the slope surface runoff take as shown in figure 1 , the energy from the top to slope Angle motion is described below.

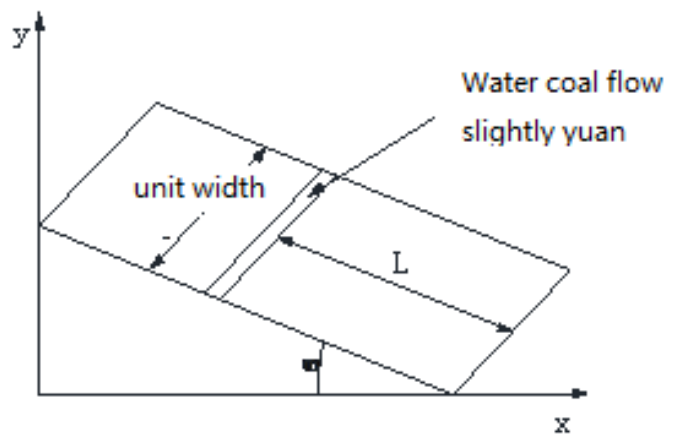

Fig.1 Water-soil stream model of slope

\subsection{Runoff scour slope surface energy}

According to the material (water and coal particles) and kinetic energy and consumption types, energy items involved in the process of slope erosion are:

(1) Static energy of coal-water two-phase flow $E_{0}$

$$
E_{0}=m_{1} g H=m_{1} g L_{x} \sin \alpha
$$

Where $m_{1}$ is coal-water two-phase flow micro-unit initial mass; $H$ is coal-water two-phase flow micro-unit initial slope height; $L_{x}$ is the distance between coal-water (2) Initial kinetic energy of water coal flow $E_{1}$

$$
E_{1}=\frac{1}{2} m_{1} v_{1}^{2}
$$

Where $v_{1}$ is initial velocity of water coal flow.

Assuming that the top of the pile width is a, slope as $\mathrm{b}$, roughness coefficient is $\mathrm{c}$, the flow over $\mathrm{t}$

$$
t_{1}=1.445 \times\left(\frac{\mu B}{\sqrt{i_{1}}}\right)^{0.467}
$$

The velocity of confluence on the top $v_{1}$ :

$$
v_{1}=2 \times \frac{B}{60 t_{1}}=\frac{B^{0.533} i_{1}^{0.2335}}{43.35 \mu^{0.467}}
$$

(3) Dissipation of frictional energy $E_{2}$

In the water coal flow, compared with water flow, the pulverized coal quantity is much smaller, so water coal flow and slope length relationship can approximate be the thought the same as the water flow and slope length relationship, are all in linear relation. As a result, the water coal flow quality in the slope at any distance $x$.

$$
m_{x}=m_{1}+\frac{m_{2}}{L} x
$$

Where $m_{x}$ is the quality of water coal flow; $m_{2}$ is the variation of water coal flow.

For the coal with rains scouring, The friction effect of the coal surface on water coal flow can be presented by slope roughness coefficient. In the process of coal water 
flow movement, the friction force is the product of positive pressure of material on the slope surface for the motion and $\mathrm{n}$ :

$$
F=n g\left(m_{1}+\frac{m_{2}}{L} x\right) \cos \alpha
$$

The friction is integrated along the movement distance, the potential energy consumed.

By friction is:

$E_{2}=\int_{0}^{L} n g\left(m_{1}+\frac{m_{2}}{L} x\right) \cos \alpha d x=n g L\left(m_{1}+\frac{1}{2} m_{2}\right) \cos \alpha$

(4) kinetic energy of water coal flow

$$
E_{3}=\frac{1}{2}\left(m_{1}+m_{2}\right) v_{2}^{2}
$$

Where $v_{2}$ the speed of water coal flow in the toe.

\subsection{Energy balance equation of the rains scouring process}

For coal hydraulic scour, hydrodynamics is directly responsible for it, other factors for indirect knock-on effect. the process of energy distribution and conversion of the rains scouring are obey the law of conservation and transformation of energy, according to the energy balance equation of mechanism of the rains scouring, coal washing and the building of energy conversion of coal washed off:

$$
E_{0}+E_{1}=E_{2}+E_{3}
$$

\subsection{The calculation model of wash load on the slope}

According to the equation (7) (9), Determine the equation:

$$
\begin{aligned}
m_{1} g L \sin \alpha+\frac{1}{2} m_{1} v_{1}^{2}= & n g L\left(m_{1}+\frac{1}{2} m_{2}\right) \cdot \cos \alpha+ \\
& \frac{1}{2}\left(m_{1}+m_{2}\right) v_{2}^{2}
\end{aligned}
$$

Solving equation(10), variation of water coal flow is available:

$$
m_{2}=m_{1} \frac{2 g L \sin \alpha-2 g L \cos \alpha+v_{1}^{2}-v_{2}^{2}}{n g L \cos \alpha+v_{2}^{2}}
$$

Duo to:

$m_{2}=\Delta m+\Delta Q=\Delta m=m_{2}-v h t_{2}$

where $\Delta m$ is wash load of coal powder; $\Delta Q$ is The addition of the rain; $t_{2}$ is Slope confluence time; $t_{2}=$ $1.445 \times\left(\frac{n L}{\sqrt{\tan \alpha}}\right)^{0.467}$.

Solving the equation(11), (12):
$\Delta m$

$$
\begin{aligned}
& =\frac{2 g L \sin \alpha-2 g L \cos \alpha+\frac{B^{0.28} i_{1}^{0.05}}{1879.2 \mu^{0.22}}-\frac{1}{n^{2}}(n I L \cos \alpha)^{0.16} \tan ^{0.09} \alpha}{n g L \cos \alpha+\frac{1}{n^{2}}(n I L \cos \alpha)^{0.16} \tan ^{0.09} \alpha} \\
& 1.445 I L \cos \alpha\left(\frac{n L}{\sqrt{\tan \alpha}}\right)^{0.467}
\end{aligned}
$$

In this formula:

$$
\begin{aligned}
& n: \text { Slope surface roughness coefficient } \\
& \mu \text { : Slope top surface roughness coefficient } \\
& I: \text { Unit width rainfall intensity }(\mathrm{m} / \mathrm{s}) \\
& L: \text { The length of the slope }(\mathrm{m}) \\
& \text { B: The width of top surface } \\
& \alpha: \text { Slope Angle } \\
& i_{1}: \text { The road transverse slope }
\end{aligned}
$$

Therefore, The function of open-air coal pulverized coal pile slope wash load is $n, \mu, I, L, \mathrm{~B}, \alpha, i_{1}$ such as variable of the function, can be represented as:

$\left.\Delta m=f\left(n, \mu, I, L, \mathrm{~B}, \alpha, i_{1}\right)\right)$

$\Delta m$ : wash load of water coal flow of Unit mass $m_{1}$.

\section{The experimental design of raining scouring \\ 3.1 The experimental equipping plan}

After the analysis of the effect of different rain on power plant coal pile, the following factors is considered in the experiment: The kinds of coal, rainfall intensity, rainfall time and the kinds of coating agent.and the experiment plan is desgind. meizhou anthracite, huangpu bituminous coal and yunfu lignite are used;The rainfall is divided into 300, 400 and $500 \mathrm{~L} / \mathrm{h}$; Increasing rainfall time for $10 \mathrm{~min}$ at every turn; Germany coating agent, domestic coating agent and wuhan university coating agent are used in the experiment to compares the effectiveness

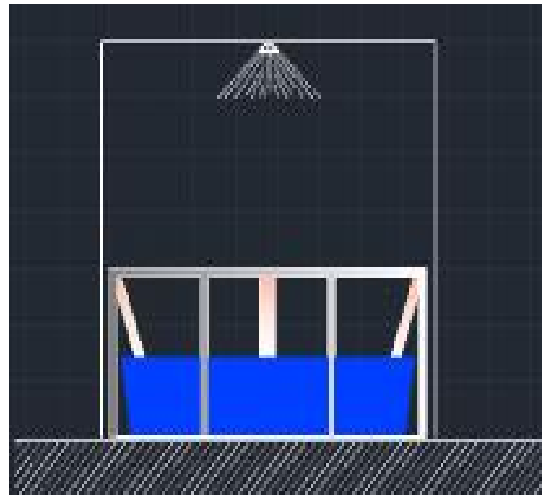

Fig. 2 The schematic diagram of the rain wash simulating process 


\subsection{Combination scheme}

All the variable conditions are considered in this experiment, the experiment species will greatly increase, and may duplicate. As shown in table 1.

Table 1 The experimental equipping plan

\begin{tabular}{|l|l|l|l|l|}
\hline Coal & $\begin{array}{l}\text { Rinfall } \\
\text { time }\end{array}$ & $\begin{array}{l}\text { Rainfall } \\
\text { intensity }\end{array}$ & $\begin{array}{l}\text { The } \\
\text { influence } \\
\text { of } \\
\text { covering } \\
\text { agent }\end{array}$ & $\begin{array}{l}\text { The kind } \\
\text { of } \\
\text { covering } \\
\text { agent }\end{array}$ \\
\cline { 1 - 1 } $\begin{array}{l}\text { yunfu } \\
\text { lignite }\end{array}$ & & & & $\begin{array}{l}\text { Germany } \\
\text { coating } \\
\text { agent }\end{array}$ \\
\cline { 1 - 1 } $\begin{array}{l}\text { huangpu } \\
\text { bituminous } \\
\text { coal }\end{array}$ & $10 / 20 / 30$ & $300 / 400 / 500$ & YES/NO & $\begin{array}{l}\text { domestic } \\
\text { coating } \\
\text { agent }\end{array}$ \\
\cline { 1 - 1 } $\begin{array}{l}\text { meizhou } \\
\text { anthracite }\end{array}$ & & & $\begin{array}{l}\text { wuhan } \\
\text { university } \\
\text { coating } \\
\text { agent }\end{array}$ \\
\hline
\end{tabular}

Therefore, in each group experiment under so many variable conditions, we need adjust the experiment scheme.

\subsection{Eperimental equipment design}

Experimental apparatus consists of two nozzle, filter cloth, bucke and the mesa of texting the coal,etc. First of all, will be washed clean bucket placed under the table on the coal. After coal in place, adjust the position of the coal. Turn on the switch, adjust the two nozzle flow to simulate rain.

The huangpu bituminous coal and yunfu lignite are used, Analyze the the loss of coal pile of two kinds of coal, via 10 mins,20mins, and 30mins washed.

Based on the analysis of rainfall size effect on the coal pile, by changing the water flow simulation. Yunfu lignite coal is selected, and separately in $400 \mathrm{~L} / \mathrm{h}, 500 \mathrm{~L} / \mathrm{h}$ flow are simulated moderate rain and heavy rain.

Yunfu lignite is chosen, covered with Germany agent, domestic coating agent and coating agent of wuhan university in China after processing, with the increasing of rainfall time: $10 \mathrm{~min}, 20 \mathrm{~min}, 30 \mathrm{~min}$. rainfall time, intensity and covering agent are analyzed affect the coal consumption.

Using the German covering agent, domestic coating agent and coating agent of wuhan university in China after processing of huangpu bituminous coal, the rainfall time with $10 \mathrm{~min}, 20 \mathrm{~min}, 30 \mathrm{~min}$ under increasing experiment, different coating agent on the degree of protection pile are analyzed.

\section{Analysis of experimental results}

\subsection{The experimental process}

(1) After each experiment, all buckets are needed to replace, the old barrel inside coal weighing with the rain, minus the quality of barrel, simulated calculation the quality of coal scoured.

(2) In the process of handling water and coal in the bottle, adding flocculating agent, Settling the coal cinder mixed with sewage, measuring the quality of coal cinder solid.

(3)Coal pile should paid attention to the same shape in each experiment.(top and bottom width, and into a perspective consistent with the ground).

According to the scheme of the experiment, spray experiment to pile should be done, and changes of sharp of coal pile should be observed. The rains scouring impact on the coal pile should be comprehensive analyzed. The actual test are shown in Fig.3.

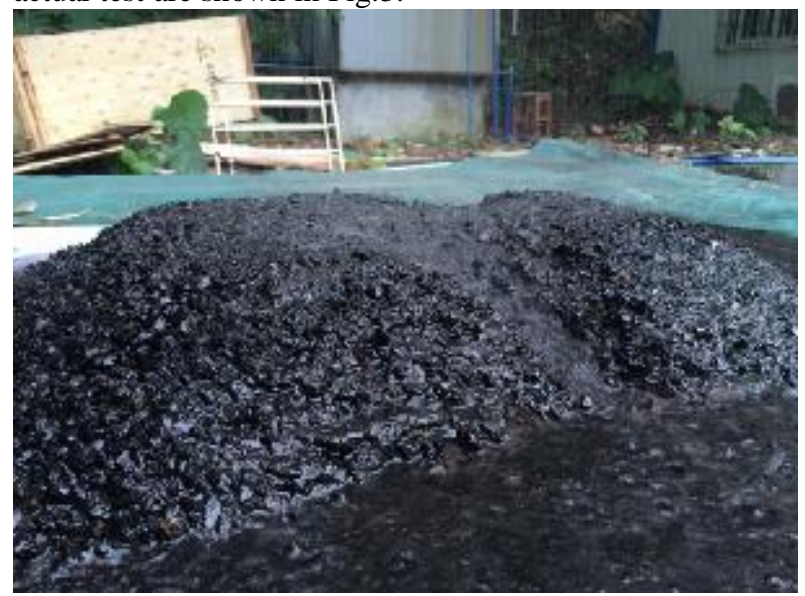

Fig.3. Coal pile after the experiment

Due to experiment and actual condition only exists similar condition, so the actual status of the experimental data is only a reference, this paper, by using the experimental data from the variables affect the trend of the situation, belong to the qualitative analysis. To reduce the loss of the power plant coal pile due to the rains scouring.

\subsection{Scouring experiment results and analysis}

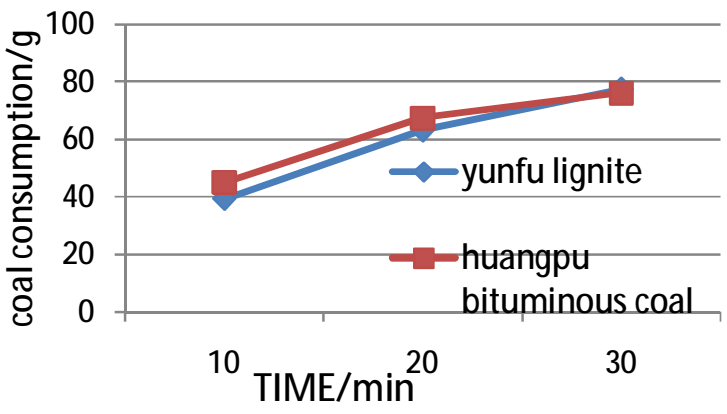

Fig 4 rain scouring time impact on the coal consumption 


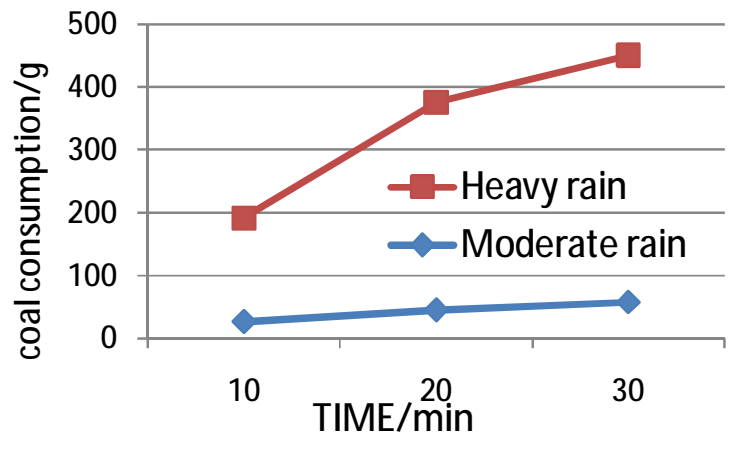

Fig5. The influence of the size of yunfu lignite coal loss of rainfall

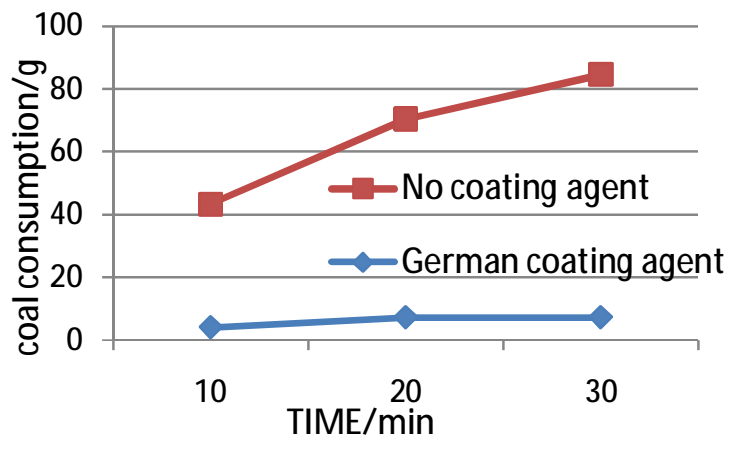

Fig6. Cover agent affect the coal consumption

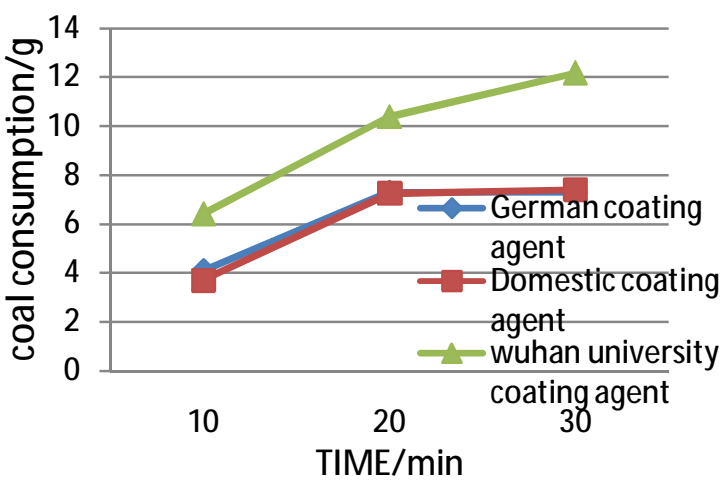

Fig7. different coating agent effect on coal consumption of contrast

\subsubsection{The rains scouring time impact on the coal consumption}

The Fig4 to 7 showed that the rains scouring time impact on the coal consumption. The main purpose of the experiment is to analyze the rains scouring effect on coal consumption of time. In order to analysis the way to improve wear. The experiment began, as a result of dry coal, a few minutes are needed before the rain soak the coal gradually. With the extension of rainfall time, after soaked in the rain, because rain erosion force, coal flushed down gradually, pile structure is broken to pieces. Along with the growth of the time, the amount of coal flushed down gradually increased. Due to previous small particles of coal are large, so, under the same rainfall duration, rainfall intensity, the first 10 min coal down is obvious more than 10 min after.

The main purpose of the experiment is to analyze the influence of different precipitation on the coal loss, Yunfu lignite coal is selected, under the the same condition of experiment, under rainfall in 400, $500 \mathrm{~L} / \mathrm{h}$. Every $10 \mathrm{~min}$ take a sample, a total of $30 \mathrm{~min}$ sampling, measuring the quality of coal washed down by water, different rainfall influence are compared on coal loss of size.Comparison of experimental results shows that with the increase of rainfall, by the amount of coal washed down is increasing, but the quality increase of coal falling down is drop.

\subsubsection{The influence of the coating agent on the coal loss}

Compared with the coal pile with covering agent and those need not covering agent, under the same rainfall and rainfall time, the coal loss treated with covering agent is much less obviously.

\subsection{3 the impact of different coating agent on coal loss of contrast}

Germany coating agent, domestic coating agent and coating agent of wuhan university in China are used to deal with coal, under the impact of the rain, every $10 \mathrm{~min}$ take a sample and measuring the quality of coal washed down, comparing different types, the effect of different coating agent.

It can be seen from figure 5, at the condition under the same rainfall intensity and rainfall, the same proportion of German covering agent and domestic covering agent for coal pile curing effects were similar, and effect of coating agent curing of wuhan university is weaker than other two kinds of coating agent.

\section{Conclusion}

By simulating the rains scouring experiment, observed the scouring process. According to the above results, summarizes the method of reduce the coal loss due to the rains scouring.

(1) Due to the coal consumption increases as the size of the rainfall, so in the upper part of the power plant coal pile with tent cover can greatly reduce the coal loss;

(2) By the curve the loss of the coal pile increased with the extension of time, so try to reduce the time of the coal pile was washed off.Specific measures can be taken that the coal pile is placed within the factory, or reduce the time of the coal pile was exposed, decrease the coal stacking;

(3) The consumption of coal treated with covering agent is much smaller than without covering agent of coal.So the use of cover agent on the power plant coal surface can significantly reduce loss;

(4) Germany coating agent, coating agent in China and coating agent of wuhan university are compared in separately, It's found that domestic covering agent and Germany coating agent effect is basically the same, and the effect of covering agent of wuhan university compared 
other two kinds of coating agent is weak. So suitable coating agent should be selected in order to reduce loss.

\section{References}

[1] Cheng Ri sheng. Ecological slope protection indoor scouring experiment research $[\mathrm{J}]$. Journal of China \& Foreign Highway.2007.10(5) 34-36.

[2] Yang Qi. Experimental study vegetation concrete rain wash resistance[J]. Soil and Water Conservation in China. 2003(1)54-56.

[3] Kong Rong et al. The design optimization of slope ecological protection of rainwater infiltration and research.Changsha, Changsha University of Science and Technology.2012.3

[4] Xing-Wu Yang. Slope soil ChongShuaLiang calculation model for analysis. [J]. Shanxi Architecture. 2009.11.107-108

[5] Liu Liling, Kun-Long Yin. Analysis of rainfall infiltration mechanism of rainstorm landslide [J]. Rock and Soil Mechanics2008, 29(4): 1 061-1 066.

[6] Liu Jian-min et al.Research on erosion calculation model of the slope on energy method[J]. China Journal of Highway and Transport.2004.17(4).21-24.

[7] Shen Shuijin et al. scouring-penetration coupling analysis of embankmentslope under rainfall action[J]. Chinese Journal of Rock Mechanics and Engineering.2011.30(12):2456-2462.

[8] XU Guang-ming, WANG Guo-li, GU Xing-wen, ZENG You-jin. Centrifuge modeling for instability of excavated slope in expansive soil due to water infiltration[J]. Chinese Journal of Geotechnical Engineering.2006, 28(2): 270-273.

[9] Zhou jian-jun, Xu Rui-chun, Liu Jing-hua. Coupling RainfallOStressOUnsaturated Seepage for Dayantang Landslide[J]. Journal of Yangtze River Scientific Research Institute. 2008, 25(6): 77-81.

[10]MONTRASIO L, VALENTINO R.Experimental analysis and modeling of shallow landslides[J].Landslides, 2007, 4(3): 291-296.

[11]MONTRASIO L, VALENTINO R.A model for triggering mechanisms of shallow landslides[J].Natural Hazards and Earth System Sciences, 2008, 8(5): 1149-1159.

[12] Liu Jun-xin, Liu Yu-tian,Hu Qi-jun. Stability of embankment slope subjected to rainfall infiltration considering bothrunoff-underground seepage and fluid-solid coupling[J]. Rock and Soil Mechanics. 2010, 31(3): 903-910. 